\title{
Disturbance of Opportunistic Small-Celled Phytoplankton in Lake Kinneret
}

\author{
Yury Kamenir and Zvy Dubinsky \\ The Mina and Everard Goodman Faculty of Life Sciences, Bar-Ilan University, Ramat-Gan 52900, Israel \\ Correspondence should be addressed to Yury Kamenir, kamenir@mail.biu.ac.il
}

Received 23 August 2012; Accepted 13 December 2012

Academic Editors: R. Dolferus, K. Pawlowski, and A. Singh

Copyright ( $) 2012$ Y. Kamenir and Z. Dubinsky. This is an open access article distributed under the Creative Commons Attribution License, which permits unrestricted use, distribution, and reproduction in any medium, provided the original work is properly cited.

In spite of the chaotic dynamics of specific populations, similarity of annual species-abundance distributions was proven for phytoplankton assemblage during a "stable" period (1985-1994) of Lake Kinneret (Israel). This similarity declined during the "extreme" years (1995-1999) that followed, characterized by explicit changes in the phytoplankton annual-succession pattern. The rank-abundance distributions of species exhibit a pronounced difference between the taxonomically rich central region, producing the reliable assemblage backbone and highly variable tails of a few species. Therefore, the distribution pattern comparison enhances the importance of ubiquitous small disturbances valuable for diagnostics. Some phyla (in this case, Cyanophyta) were especially vulnerable to structural changes. A simple disturbance index was constructed, based on opportunistic small-celled species. The fine-structure disturbances, which can provide early-warning information, are discussed.

\section{Introduction}

Ever-growing anthropogenic pressure causes pronounced changes in natural ecosystems on both local and global scales. Some of these changes are undesirable and even dangerous. Such a situation demands scientific tools for quantitative estimations, ecological forecast, and diagnostics of aquatic assemblage structural changes.

Size-spectrum (Figure 1) analysis [1] is one of the tools capable of encompassing the whole assemblage and supporting various quantitative studies. Large-scale size-spectrum studies have demonstrated the inherent typical patterns in the biomass size spectrum and its normalized variant, describing aquatic communities of very different natures and spatial scales $[1,2]$. While "ataxonomic" biomass spectra ignore the taxonomic affiliation of organisms, another type of size structure, specifically, size-frequency distributions of species and other taxonomic units, have also been studied for a long time and exhibit common patterns [3]. These patterns also seem to be capable of surviving strong environmental stress and some forms of anthropogenic regulations [4]. The interspecific frequency distributions of animal body sizes have attracted much attention of ecologists and evolutionary biologists. Broad-scale comparisons of invariant size-frequency distributions of species have already been established for several terrestrial and aquatic assemblages $[3,5]$. Common patterns, following one of the oldest and most universal laws, were also found for species-abundance distributions, including the rank-abundance distribution and the respective histogram based on the species-abundance classes $[6,7]$.

Comparisons of several types of species distributions enhance better appreciation of the vulnerability of the aquatic assemblage. We have already applied several types of taxonomic and ataxonomic distributions to analyze the phytoplankton of subtropical Lake Kinneret, Israel [8, 9]. Our comparative studies have shown (Figure 1) that a few smallcelled species dominate the cell-abundance spectra, and several large-cell species make up the bulk of the assemblage biomass, whereas many rare species with low biomass and population abundances increase assemblage diversity $[8,9]$. Three zones, in which 2 opposite tails include a small number of species, while the central size region encompasses the community main taxonomical store, are discernible 


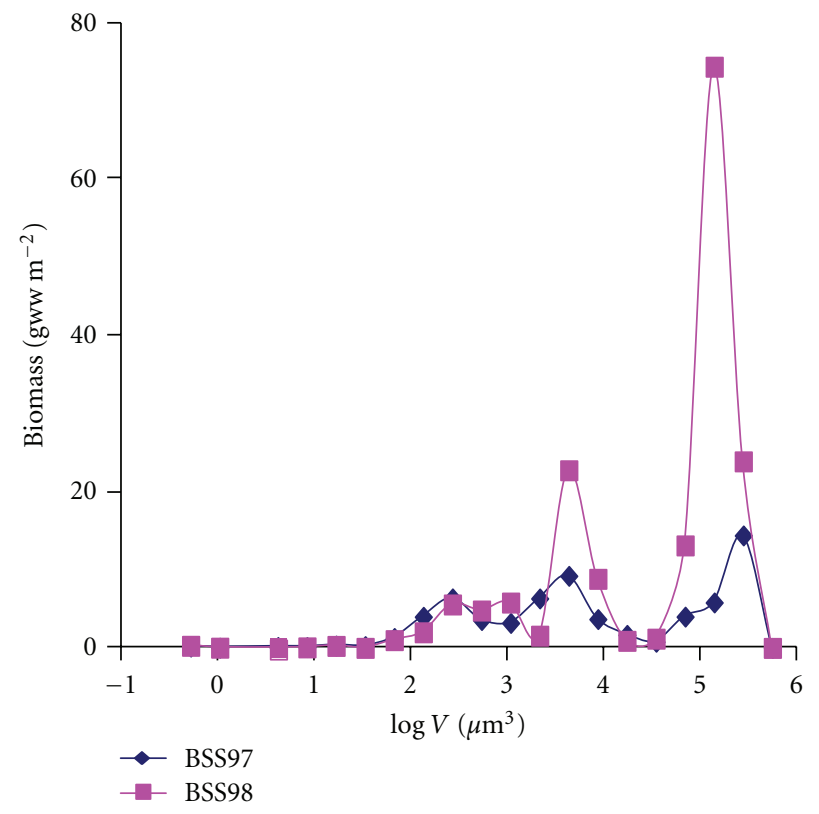

(a)

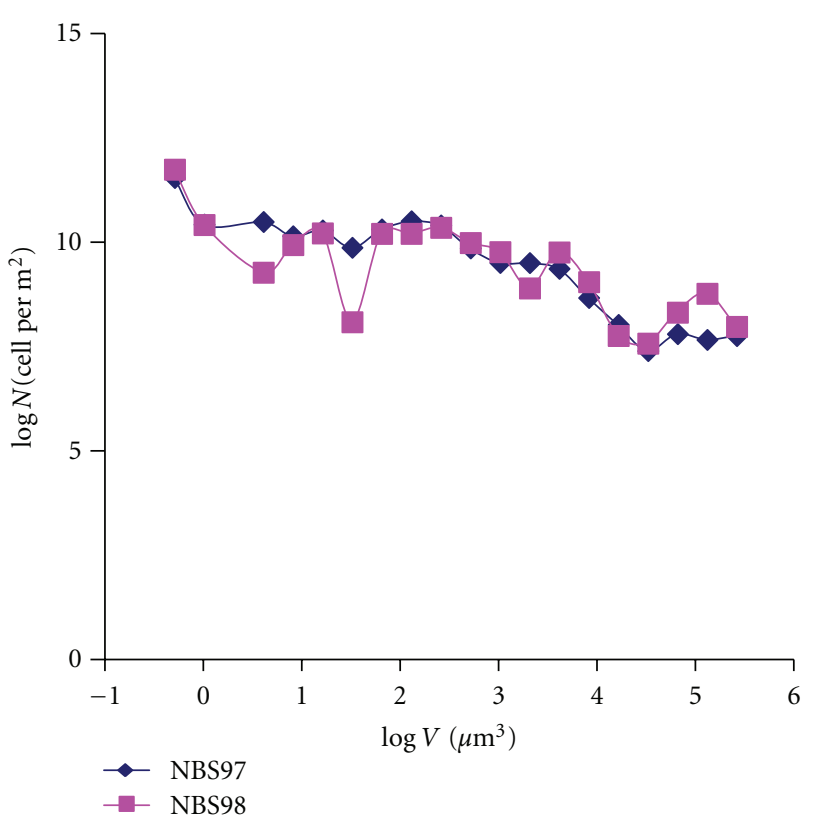

(b)

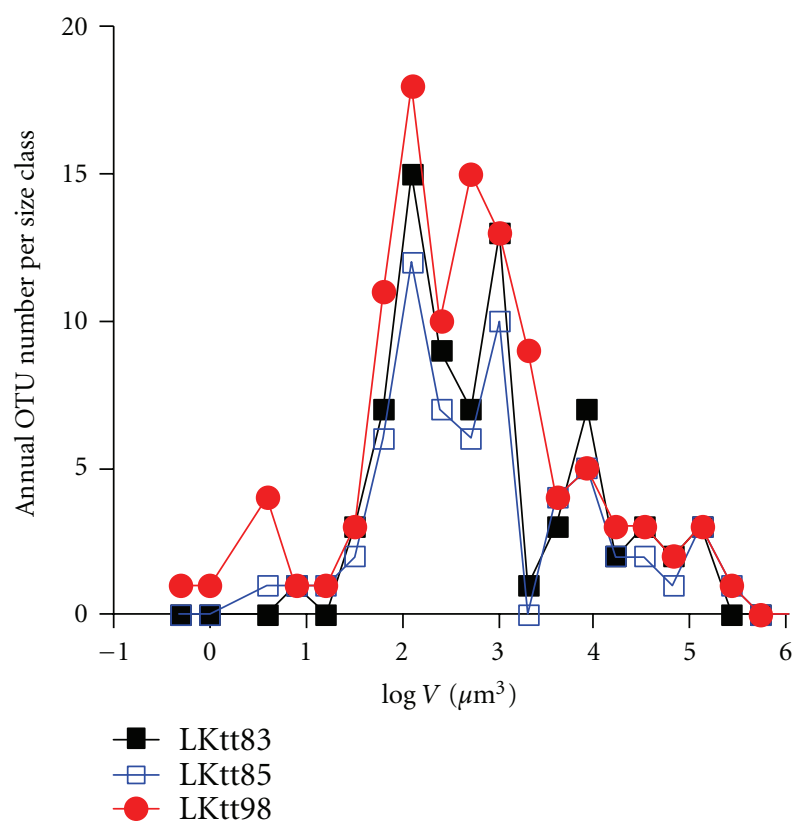

(c)

Figure 1: Comparisons of annual size spectra. (a, b) The "Sheldon" and normalized biomass size spectra, respectively, for extremely disturbed years, 1997 and 1998 (after [8]). The biomass size spectrum describes the assemblage biomass distribution to size classes of cell volume logarithm, and the normalized biomass size spectrum can be interpreted as the cell abundance ( $N$ cell) distribution approximation. (c) The traditional taxonomic size-spectrum (TTSS) change for representative years of the stable (1983, 1985) and extremely disturbed (1998) periods (after [9]). The curves are marked by the year they represent (yy). All phytoplankton species with cell size $\geq 2 \mu \mathrm{m}$ and colonial species of smaller cell size are included, but not unicellular picoplankton. Size classes were created by doubling cell volume $(V)$ and are presented on a logarithmic scale $\left(\log _{10} V\right)$.

(Figure 1(c)). While the central region shows rather stable cell-abundance curve (Figure 1(b)), both peripheral zones exhibit pronounced variability of the curve. The right tail of the cell-size scale, describing very large cells $(\log V>4)$, contained the main part of the biomass (Figure 1(a)). In contrast, the left-hand tail seemed to be nonsignificant if the biomass was the main criterion; however, both the cell abundance and species number demonstrated high vulnerability at that size range (Figures $1(\mathrm{~b})$ and $1(\mathrm{c})$ ).

The notable similarity of the assemblage taxonomic structure patterns (Figure 1(c)) agrees well with the stability of the assemblage ataxonomic size structure (Figure 1(b)), 
while it is in contrast to the well-known empirical data and mathematical models considering a very high variability and chaotic dynamics of the assemblage populations [10-12]. Whereas the response of the average lake communities to environmental impacts is often quite predictable, the algal community dynamics on the species level usually seems to be erratic [12]. Therefore, the similarity of the wholeassemblage taxonomic or ataxonomic spectrum general pattern looks especially valuable for purposes of modeling and prediction. At the same time, comparisons of small details in the pattern fine-structure can highlight diagnostically important traits.

A fundamental problem of environmental science is to characterize the anthropogenic impacts on aquatic communities in a quantitative way, providing detection of disturbances at an early stage $[13,14]$. While biomass is used as a traditional criterion, some species often demonstrate very high and very variable abundances [15]. Such cellabundance variability seems suitable for providing earlywarning information. The cell-abundance distributions can serve to obtain insights into disturbance analysis and perturbation diagnostics [7]. The departure from the lognormal distribution [6] was suggested as providing indices of pollution [13]. The assemblage-perturbation index, based on opportunistic species [14], was produced from a small number of species.

The well-documented stable pattern of Lake Kinneret annual succession was maintained during many years (1969-1992), accompanied with the 1993-94 anthropogenic impacts and subsequent disturbed years [15-17]. The longterm record of the Kinneret can be used to validate hypotheses considering the phytoplankton composition reaction on increased anthropogenic stress. Some parts of phytoplankton (phyla) positioned at specific regions of taxonomic distributions can be especially sensitive under disturbances and, therefore, valuable for diagnostics.

In this new work, we attempted to select and compare the species distribution patterns of the most interesting parts of a lake phytoplankton assemblage, as seen from long-term monitoring.

The general aim of the study was a search for diagnostically valuable quantitative changes in specific taxonomic structure patterns based on species abundance of Lake Kinneret (Israel) phytoplankton.

The working hypothesis was that some distinctions between consistent backbone and diagnostically valuable parts of phytoplankton taxonomic structure can be ascertained. A simple quantitative index can be developed to estimate community disturbance.

\section{Methods}

2.1. Site Description. Lake Kinneret, Israel, situated ca. $210 \mathrm{~m}$ below sea level at $32^{\circ} 45^{\prime} \mathrm{N}, 35^{\circ} 30^{\prime} \mathrm{E}$ [16], is a warm, monomictic lake with a surface area of $170 \mathrm{~km}^{2}$, maximum depth of $44 \mathrm{~m}$, and mean depth of $26 \mathrm{~m}$. The lake, which is used for recreation and fishery, is also the main source of drinking water in Israel, and its water quality is of prime national importance. Therefore, a routine program to monitor numerous biotic and abiotic parameters has been carried out since 1969. From the beginning of this monitoring program, Kinneret phytoplankton have exhibited distinct stability of species succession and biomass-dynamics annual patterns [17]. However, numerous human-induced regulations and climatic changes have led to drastic modifications in phytoplankton succession. Two major perturbations that affected the Kinneret ecosystem were the collapse of the Kinneret fisheries (1993) as a result of overfishing, and the reflooding of the dried peat soils of the Hula Valley in the lake's catchment (1994), leading to changes in amounts and contents (nutrients, heavy metals, and organic matter) of water flowing into the lake [15]. After 1994, these modifications were expressed in the pronounced interannual variability in phytoplankton biomass dynamics. The most notable changes included the absence of the prevailing spring Peridinium gatunense blooms in some years, their recordhigh intensification during some other years, intensification of winter Aulacoseira granulata blooms, replacement of the summer species assemblage of mostly nanoplanktonic palatable cells with less palatable forms, proliferation in summerfall of $\mathrm{N}_{2}$-fixing, toxic cyanobacteria, and so forth [15].

For this study, we chose to focus on a long (15 years), continuous time interval consisting of two parts, referred to as the "stable" period (1985-1994) and the "extreme" period that followed (1995-1999). The extreme period and one of the previous years (1985) had been already subjected to sizespectrum analyses. The data, methods, and revealed typical patterns of biomass and taxonomic size-spectra of the whole phytoplankton assemblage were described in $[8,9]$.

2.2. Phytoplankton Data Acquisition and Processing. As part of the routine monitoring program, phytoplankton samples were collected biweekly using a 5-L bathometer at a fixed pelagic station at the deepest part of the lake, from 9-11 discrete depths throughout the water column. Microscopic counting of Lugol-preserved samples was produced using inverted microscope [15]. All phytoplankton species with individual cells greater than $2 \mu \mathrm{m}$ in diameter were identified and counted according to species, and for the more abundant species with variable cell size-also according to size categories. Since our individual taxon is not strictly a species but in some cases also a size category within a species, we refer to each as an operational taxonomic unit (OTU) [18]. From the smaller cell range, only the relatively common colonyforming cyanobacteria were included. Sample processing was described in detail in $[9,15]$.

2.3. Species-Abundance Distributions. Species-abundance distributions of all OTUs encountered within a community were developed. We applied the annual maximal abundance estimates $\left(N_{j}\right.$, cell per $\left.\mathrm{mL}\right)$ in order to amplify sensitivity while looking for opportunistic and other disturbancesensitive species. The dependence of maximal annual species abundance $\left(N_{j}\right)$ on its typical cell volume $\left(V_{j}\right)$ have been described via scatter plots and linear regressions. Each annual rank-abundance distribution was created of all OTU 


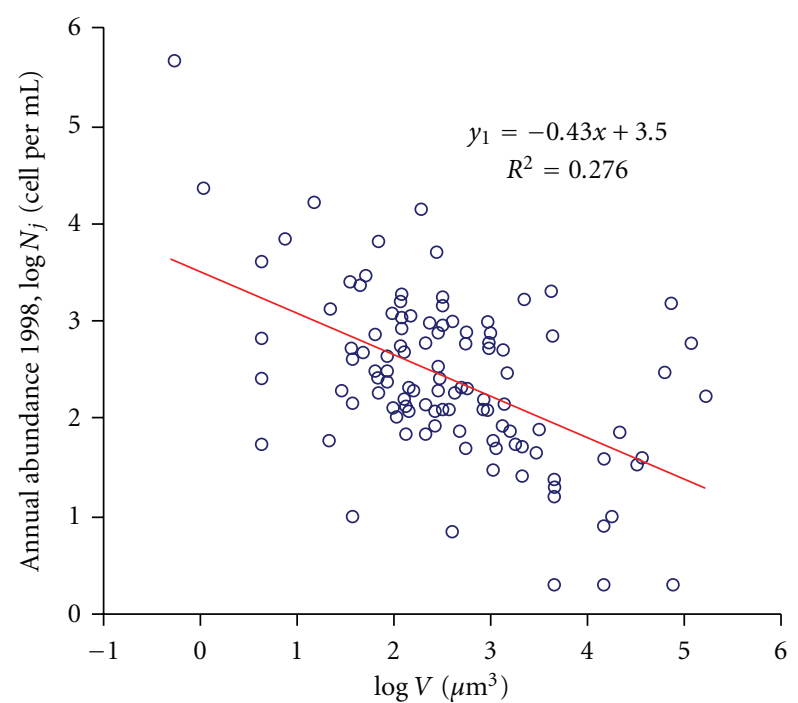

(a)

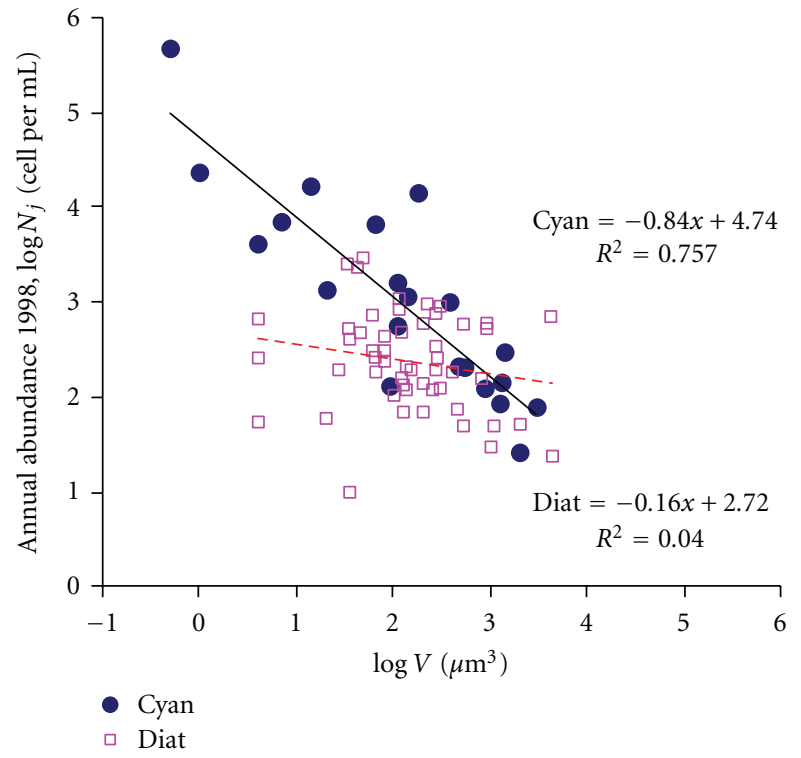

(b)

Figure 2: Scatter plots of maximal cell abundance of each species $\left(N_{j}\right)$ versus its cell volume $\left(V_{j}\right)$, for a disturbed year (1998). (a) All phytoplankton. (b) Smallest algae-Cyanophyta (Cyan) and diatoms (Diat). Both axes are log-transformed.

registered during one year, sorted in the descending order of the species abundances $\left(N_{j}\right)$. Each annual species abundance distribution was also plotted as a histogram of species on the $y$-axis versus cell abundance using logarithmic $x$-axis [7]. The size class corresponds to an octave, that is, duplication of the abundance [6].

A modified assemblage disturbance index, based on opportunistic species [14], was produced. The disturbance index was calculated as the average value of 5 logtransformed abundance dominants (ranks 1-5). The difference between the index values of the 1st year (1985) and each following year (i.e., first 5 pairs of log-transformed abundances) was compared by paired $t$-test. The difference between the disturbance indices of 2 groups of 5 years was tested by two-sample two-sided $t$-test. The SPSS program, version 15.0 (SPSS Inc., Chicago, IL 60606, USA), was used for all statistical procedures.

\section{Results}

Scatter plots of maximal annual cell abundance of each species $\left(N_{j}\right)$ versus cell volume $\left(V_{j}\right)$ have shown a very high variability-almost 6 orders of $N_{j}$ magnitude for the whole phytoplankton assemblage, including 4 orders for 1 size fraction (Figure 2(a)). Only very few species had $\log N_{j}>4$, all of them being small species, $\log V_{j}<2$. The smallest algae were presented by two phyla-Cyanophyta and Bacillariophyta. These 2 phyla demonstrated very different $N_{j}$ versus $V_{j}$ trends: an almost horizontal trend for Bacillariophyta and a very steep negative trend for Cyanophyta (Figure 2(b)). Almost horizontal trends were also shown to several small phyla in the central cell-size region (Chlorophyta, Cryptophyta, Prasynophyta, and Haptophyta); the largest algae (Dinophyta) demonstrated even an opposite trend.
Two 5-year (stable and extreme) periods (1990-1994 and 1995-1999, Figures 3(a) and 3(b), resp.) represent annual histograms of the species number distribution between abundance octaves (i.e., cell-abundance duplications), where each OTU was presented by its annual maximal abundance value $\left(N_{j}\right)$. While the general pattern was almost unchanged, each annual histogram presented slightly different shape (Figure 3(a)). The extreme period (1995-1999, Figure 3(b)) produced more different and symmetrical bells; the last year (1999) exhibited a higher and thinner bell. The most clear distinction between the two periods (Figures 3(a) and 3(b)) was the length of the histogram right tail.

The increase of the highest abundances was also especially conspicuous on the rank-abundance distributions of the stable and extreme periods presented for each annual dataset (Figures 3(b) and 3(c), resp.). The rank-abundance curves produced almost the same shape during the stable years, while the extreme years exhibited much more variable shapes. A notable peculiarity was a sharp division of each curve to 3 parts of considerably different steepness. The middle region exhibited a very gentle, almost straight line suitable for a linear regression. At the same time, the right tail was convex and long, while the very steep left-hand tail was formed by the first 5-7 leading species. The middle part was exceptionally long for years 1998 and 1999, while unusually short for 1990.

After that, the histograms of the 2 periods (a) and (b) were compared using the 5-year average estimates (Figure 3(e)). The general pattern of the 2 histograms was almost the same, however, for the extreme period, the bell was broader due to the left slope movement, and the right-hand tail was longer. The disturbance index was calculated for each annual dataset. The index values for 15 consecutive years were compared with the horizontal 


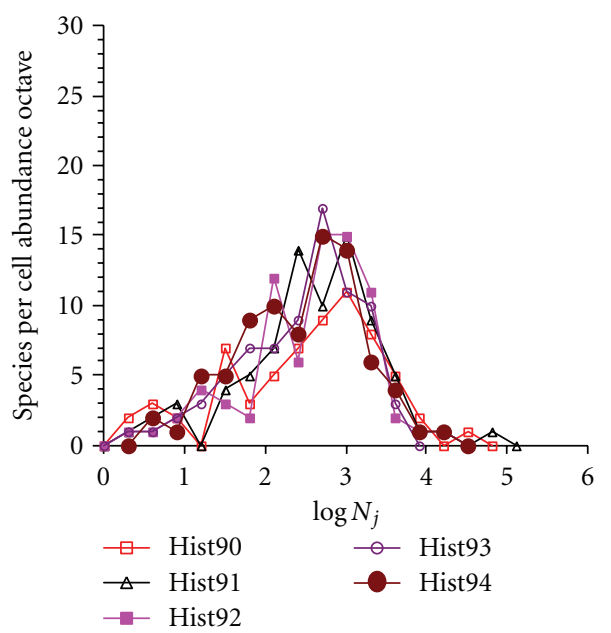

(a)

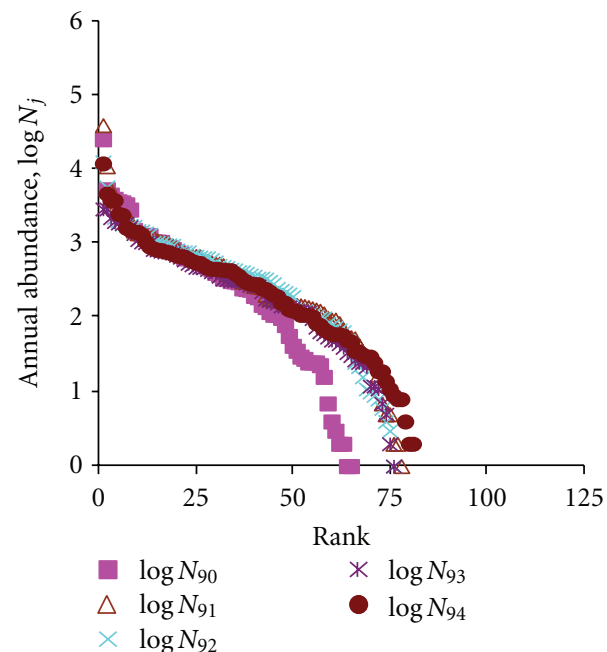

(c)

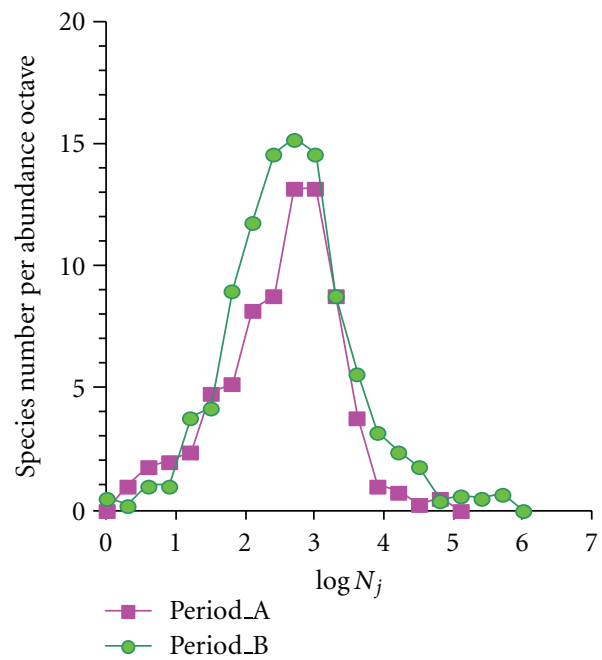

(e)

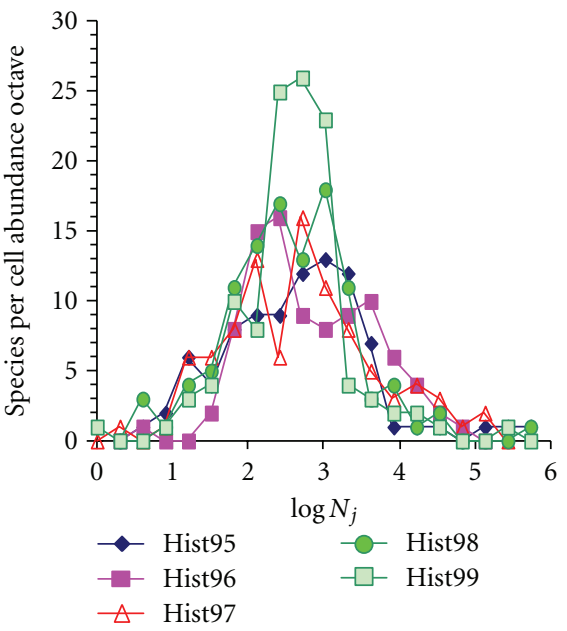

(b)

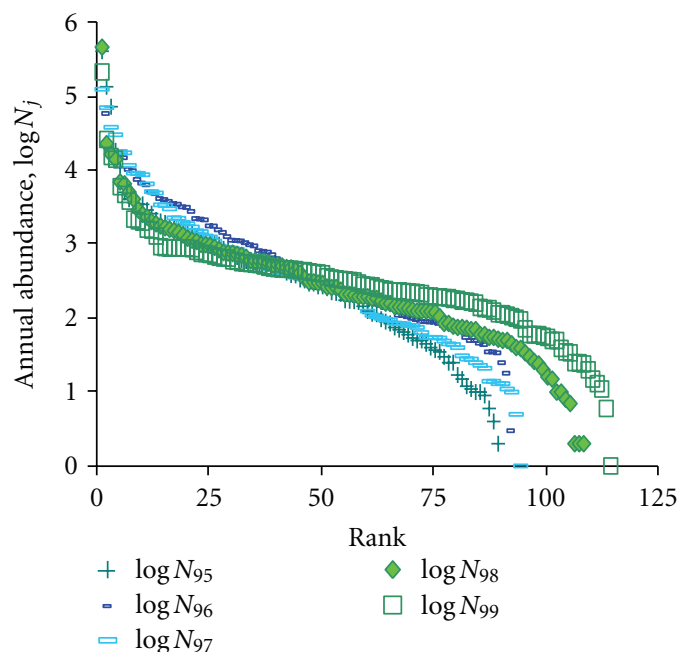

(d)

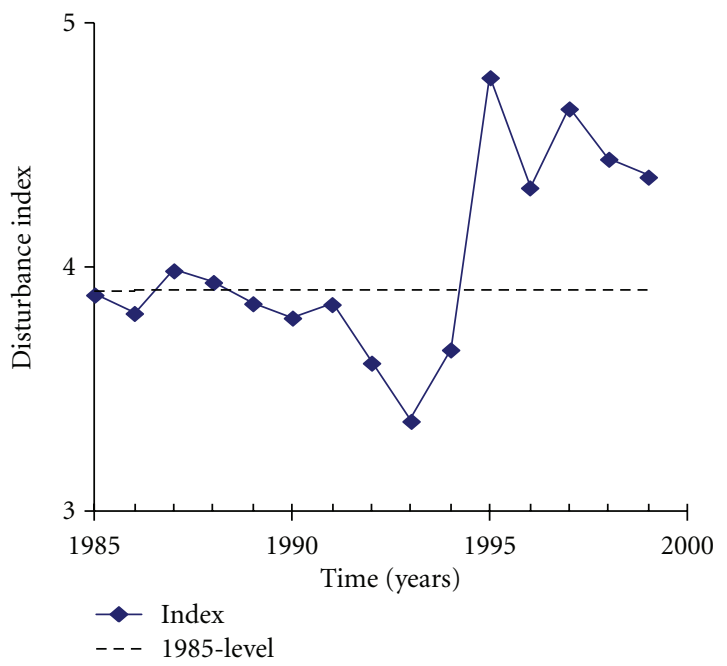

(f)

FIGURE 3: Species-abundance distributions of Lake Kinneret phytoplankton. Histograms of species abundance, representing species-number distribution according to octaves (i.e., cell abundance duplications), for 2 periods ( $a, b)$. (c, d) Rank-abundance distributions of species for the stable and the following disturbed periods. (e) The 5-year (see plates (a, b)) average histograms of species abundance. (f) Phytoplankton disturbance index, representing the average value of 5 leading abundances (see the Methods), in comparison with the index level for 1985. 
line corresponding to the year 1985 (Figure 3(f)). A drastic change of the index values characterized the extreme period of 1995-1999, and even the preceding years (1992-1994). The difference between 2 groups of 5 years (1989-1993 and 1995-1999) was statistically significant (two-sample $t$-test, $P<0.001, n=10)$. The difference between index values (i.e., 5 log-transformed abundance dominants) of year 1985 and each following year was significant (paired $t$-test, $n=5$ ) for the years 1993 and $1998(P<0.05)$ and 1992, 1995-1997 and $1999(P<0.01)$.

\section{Discussion}

The abundance-versus-volume scatter plot shows that the majority of species occupy the center of the phytoplankton cell-volume range (Figure 2(a)). Only several large species (mainly Dinophyta) occupy the right tail $(\log V>4)$, where the main part of total biomass is concentrated (Figure 1(a)). The opposite side of the size range also contains very few species, including the abundance dominants. One of the phyla-Cyanophyta-looks like conquerors, trying to capture the left-side extremity (from $\log V=3$ to $\log V<$ 0 ) by very few species (Figure 2(b)), producing a very low biomass of a species and size class (Figure 1(a)), but record high species abundances (Figure 2). While the biomass serves as a traditional criterion for the assemblage disturbance analysis (e.g., bloom of Dinophyta) — especially conspicuous at the right tail $(\log V>4)$-the opposite tail, describing small cells $(\log V<1)$, can also be used to diagnose the assemblage disturbance.

Statistically significant differences between the annual average estimates of the stable and extreme periods were found for several environmental variables: the lake water level, its phosphorous load, chloride concentration, and surface layer temperature [15]. The nutrient stoichiometry and the rising water temperature seem to be plausible factors favoring some Cyanophyta species.

The increase of the abundance dominants was especially conspicuous while comparing the stable and extreme periods (1990-1994 and 1995-1999, respectively, Figures 3(c), and 3(d)). The species distribution histograms (Figure 3(e)) had almost the same general pattern for 2 periods; hence, the fine structure change seems to be meaningful. The histogram$\mathrm{B}$ left slope moved leftwards due to the addition of a number of new OTUs with relatively small abundances $\left(\log N_{j}<3\right)$. This change can be seen on the rank-abundance distributions (Figure 3(d)) since their middle region length and slope changed due to the addition of several species with low abundances $\left(\log N_{j} \sim 2-3\right)$ supplemented by very few abundance champions $\left(\log N_{j}>4\right)$. Such changes can be interpreted as the morphological diversity growth obtained by very few opportunistic populations supported by several populations with much lower abundances. The new species are mainly Cyanophyta which flourished after 1994 (Figure 3(d)). The length of the histogram right-hand tail can serve as a quantitative disturbance indicator.

Species-abundance distributions were considered by numerous specialists as promising for significant insights into basic and applied ecological science [7]. Considering the pattern changes, we can calculate several characteristics of each distribution (slopes of each region, the central part length, and its linear regression determination coefficient). Then, such indices (e.g., the distribution top-end height) can be easily estimated, therefore, their changes can be used for diagnostics and require a more detailed analysis. The rank-abundance curve left-hand tail was especially steep and short (Figure $3(\mathrm{~d})$ ), consisting of only 5-7 species. As a rule, these were small diatoms and Cyanophyta, mainly Microcystis spp., widely known as common harmful algae. A drastic change of the disturbance index values characterized the extreme period of 1995-1999 (Figure 3(f)). The early warning information can be seen for several preceding years (1992-1994). The causes of the disturbance-index changes for several years before the apparent changes of the biomass succession deserve additional studies.

\section{Conclusions}

The whole-assemblage species abundance distributions demonstrated a high level of similarity; the distribution pattern changes become evident only during periods of extreme changes of the phytoplankton assemblage annual succession. At the same time, the species-list variation is notable even during the stable period. In such a system, the phylum appears to be an intermediate level of optimal sensitivity, suitable for the aims of assemblage structural-similarity estimation. Some phyla (Cyanophyta, in our case) demonstrate especially high sensitivity at Lake Kinneret.

The species-abundance distributions can be helpful in measuring phytoplankton-structure disturbances. Distinction between the rank-abundance distribution backbone and its two extremities helps construct simple quantitative indices suitable for diagnosis of assemblage disturbances.

\section{Acknowledgments}

The authors thank Eva Feldman and Tatiana Fishbein, who conducted the phytoplankton counts as part of the Kinneret monitoring program funded by the Israel Water Commission. They are grateful to Kirill Khailov, Danara Krupatkina, Oleg Makarov, Giuseppe Morabito, and Yosef Yakobi for valuable discussions and advice.

\section{References}

[1] R. W. Sheldon, A. Prakash, and W. H. Sutcliffe, "The size distribution of particles in the ocean," Limnology and Oceanography, vol. 17, pp. 327-340, 1972.

[2] S. R. Kerr and L. M. Dickie, The Biomass Spectrum: A PredatorPrey Theory of Aquatic Production, Columbia University, New York, NY, USA, 2001.

[3] J. H. Brown, Macroecology, Chicago University, Chicago, Ill, USA, 1995.

[4] T. D. Havlicek and S. R. Carpenter, "Pelagic species size distributions in lakes: are they discontinuous?" Limnology and Oceanography, vol. 46, no. 5, pp. 1021-1033, 2001.

[5] L. L. Chislenko, Structure of Fauna and Flora as Related to the Sizes of Organisms, Moscow University, Moscow, Ruissa, 1981. 
[6] F. W. Preston, "The commonness, and rarity, of species," Ecology, vol. 29, pp. 254-283, 1948.

[7] B. J. McGill, R. S. Etienne, J. S. Gray et al., "Species abundance distributions: moving beyond single prediction theories to integration within an ecological framework," Ecology Letters, vol. 10, no. 10, pp. 995-1015, 2007.

[8] Y. Kamenir, "Stability of Lake Kinneret phytoplankton structure as evidenced by several types of size spectra," Fundamental and Applied Limnology, vol. 168, no. 4, pp. 345-354, 2007.

[9] Y. Kamenir, Z. Dubinsky, and T. Zohary, "Consistent annual patterns of water mass occupancy are revealed by taxonomic units of Lake Kinneret phytoplankton," Israel Journal of Plant Sciences, vol. 56, no. 1-2, pp. 91-101, 2008.

[10] R. Heerkloss and G. Klinkenberg, "A long-term series of a planktonic foodweb: a case of chaotic dynamics," Internationale Vereinigung für Theoretische und Angewandte Limnologie, vol. 26, pp. 1952-1956.

[11] J. Huisman and F. J. Weissing, "Fundamental unpredictability in multispecies competition," American Naturalist, vol. 157, no. 5, pp. 488-494, 2001.

[12] M. Scheffer, S. Rinaldi, J. Huisman, and F. J. Weissing, "Why plankton communities have no equilibrium: solutions to the paradox," Hydrobiologia, vol. 491, pp. 9-18, 2003.

[13] J. S. Gray, "Detecting pollution induced changes in communities using the log-normal distribution of individuals among species," Marine Pollution Bulletin, vol. 12, no. 5, pp. 173-176, 1981.

[14] K. I. Ugland, A. Bjørgesæter, T. Bakke, B. Fredheim, and J. S. Gray, "Assessment of environmental stress with a biological index based on opportunistic species," Journal of Experimental Marine Biology and Ecology, vol. 366, pp. 169-174, 2008.

[15] T. Zohary, "Changes to the phytoplankton assemblage of Lake Kinneret after decades of a predictable, repetitive pattern," Freshwater Biology, vol. 49, no. 10, pp. 1355-1371, 2004.

[16] C. Serruya, Ed., The Kinneret. Monographia Biologica, Junk, The Hague, The Netherlands, 1978.

[17] T. Berman, L. Stone, Y. Z. Yacobi et al., "Primary production and phytoplankton in Lake Kinneret: a long-term record (1972-1993)," Limnology and Oceanography, vol. 40, no. 6, pp. 1064-1076, 1995.

[18] P. H. A. Sneath and R. R. Sokal, Numerical Taxonomy, Freeman, San Francisco, Calif, USA, 1973. 

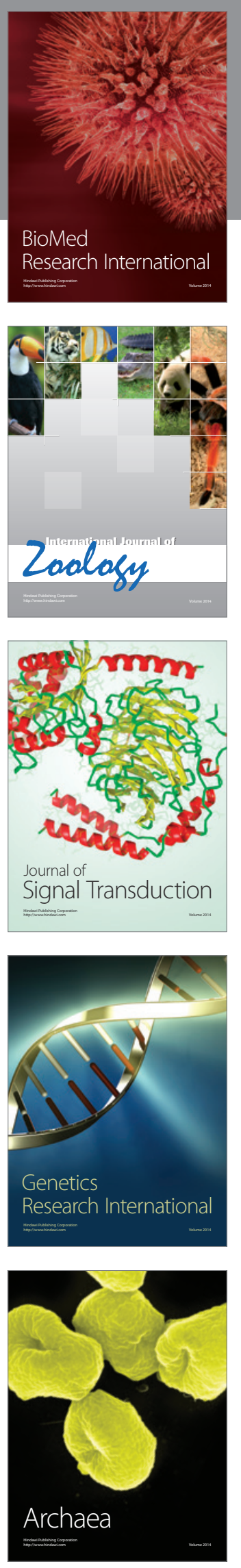
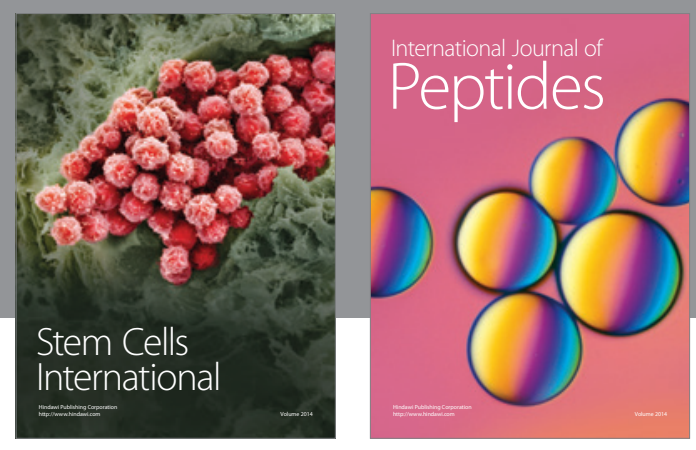

Submit your manuscripts at

http://www.hindawi.com
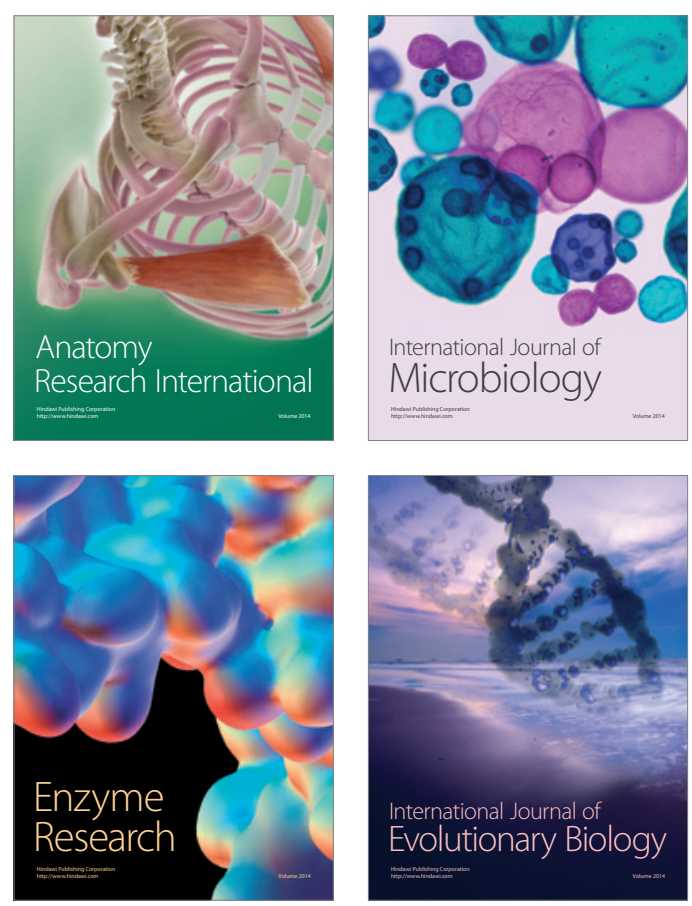
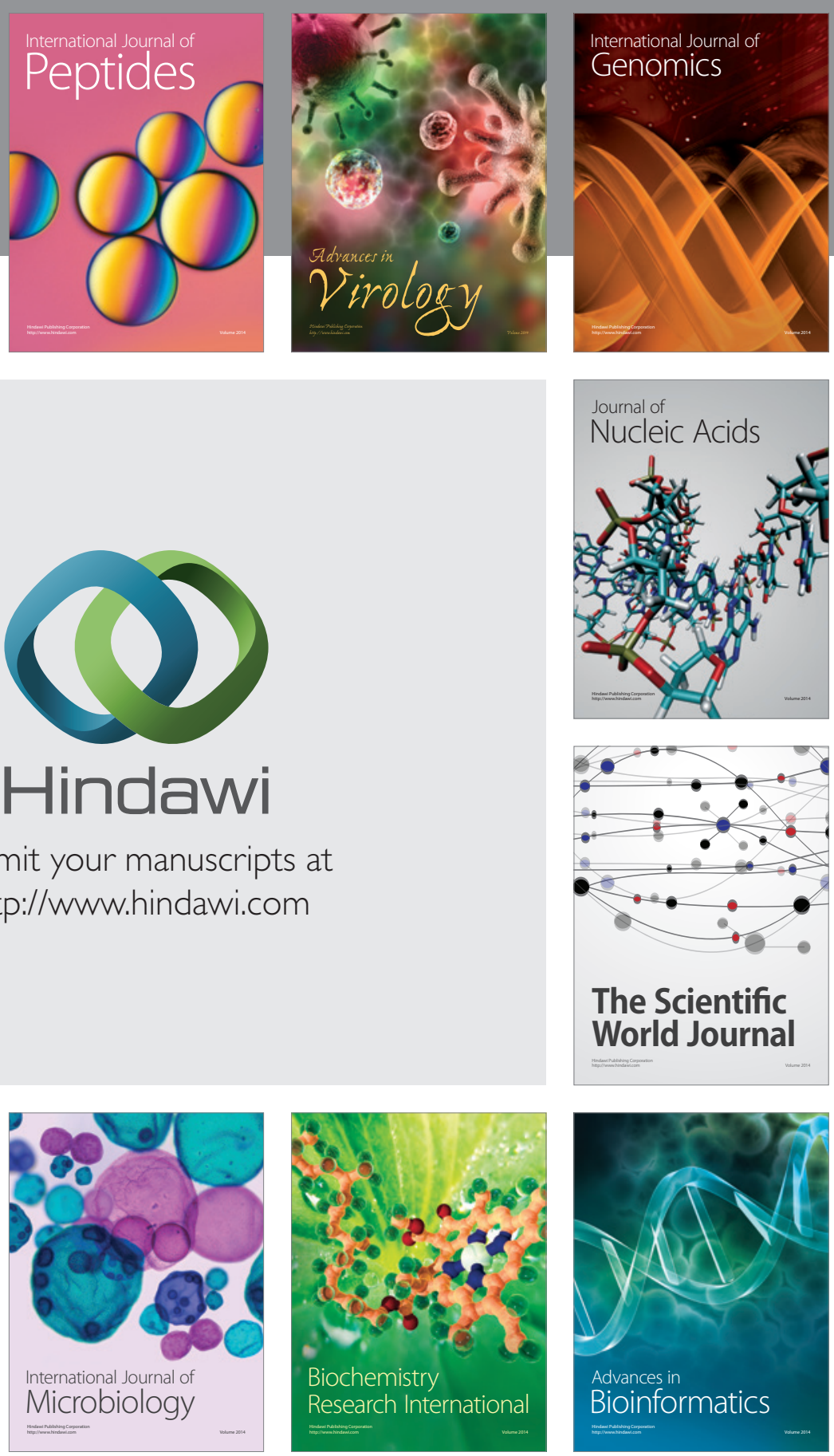

The Scientific World Journal
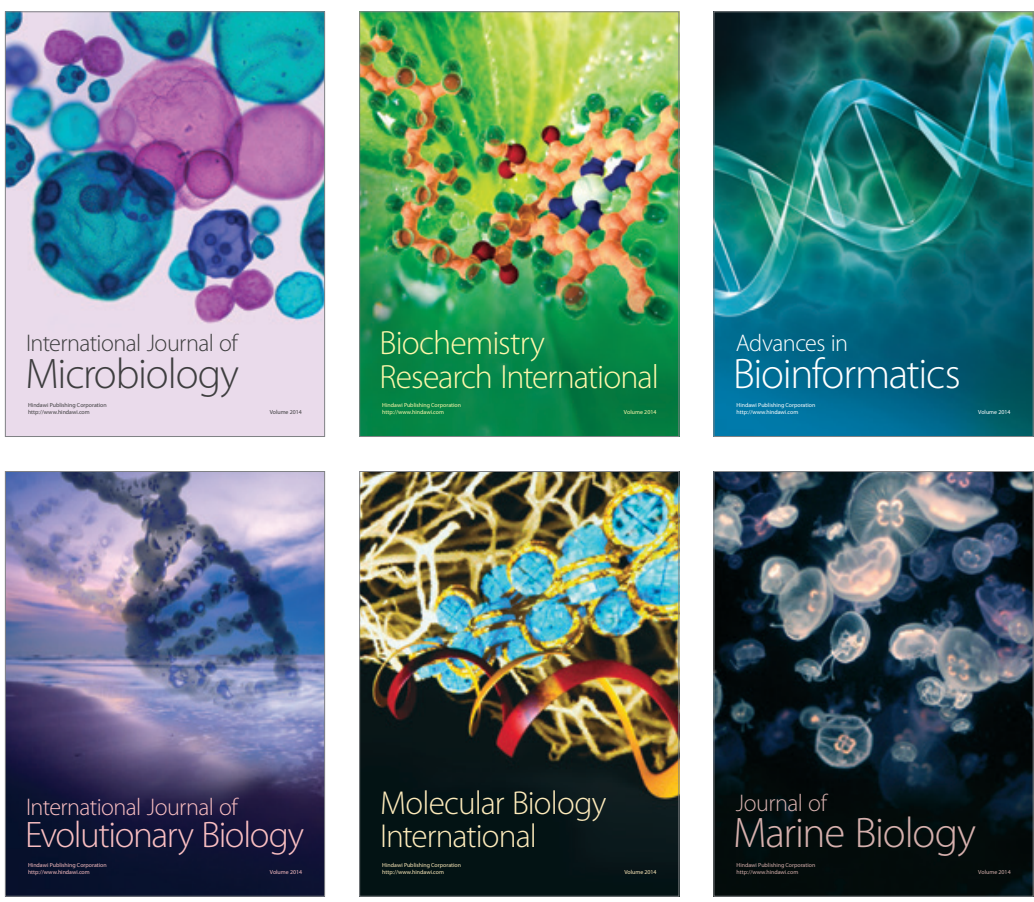